\title{
Narrating Sensitive Topics
}

\author{
Margareta Hydén \\ Book Chapter \\ Tweet
}

N.B.: When citing this work, cite the original article.

Part of: Doing Narrative Research, Molly Andrews, Corinne Squire and Maria Tamboukou (eds), 2008, pp. 121-136. ISBN: 9781412911962

Copyright: Sage Publications

Available at: Linköping University Electronic Press http://urn.kb.se/resolve?urn=urn:nbn:se:liu:diva-42616 
Published in: Andrews, M.; Squire, C. \& Tamboukou, M. (2013). Doing Narrative Research. Second Edition. Pp. 223-239- London: Sage.

\section{Narrating Sensitve Topics}

\section{Margareta Hydén}

I can still recall the scent of dry heat that so intensively flavoured that day in July 1971 when I first met Maria. ${ }^{1}$ I can hardly think of an encounter more embed- ded in incongruence. I was a very inexperienced social work student of 23 years, working for the summer at a shelter for homeless women with drug problems. She was a 26-year-old experienced sex worker. She was nine months pregnant with her second child and seeking refuge because she needed a safe place to stay awaiting the delivery of her child. Her plan was to give the baby up for adoption immediately after its birth. I had no children, lived in a cozy little apartment with my husband and spent my days at Stockholm University. The streets of Stockholm and a van were her regular working sites.

Maria and I spent a great deal of time alone over the following days. Everyone but us seemed to be on vacation, staff and guests alike. We had time to talk. Maria gave me detailed accounts of the kind of work she did, emphasizing that she was a 'real professional'. Sex did not seem to be a sensitive topic for her. She invited me to join her in talking about sex and to share my best sexual experiences. Her invitation made me very embarrassed: such private, sensitive issues - should I talk about them with a stranger? No way. I do not remember her showing any signs of understanding or sensitivity towards my embarrassment. She simply continued. I tried to introduce some more neutral topics into our conversation, like 'Where did you grow up?' or 'A new episode of the TV-series everybody talks about is com-ing on, maybe we should watch it'. I had no success in my efforts, however. Topics like those I picked only seemed to irritate and

\footnotetext{
${ }^{1}$ All names have been altered for reasons of anonymity.
} 
almost embarrass her. 'My child-hood wouldn't interest you a bit and I don't watch TV in the van', she snapped.

Maybe she wanted to talk more about her children. I deliberately avoided the topic. I found it heartbreaking that in a few days she would give birth to the child she had carried for nine months and immediately give him or her up for adoption. I could not think of a more sensitive topic. Finally, I reluctantly brought it up - 'You are giving your child up for adoption? - and got a prompt answer. 'I already have a son', she said, 'so I'd like a girl this time. I want my children to have good homes, good upbringings. I am definitely not the right person to give them good lives. You know, I don't know who their fathers are and I live in a van. What kind of life is that for a child? By the way, do you have any idea how difficult it is to be approved as an adoptive parent? First they have to fill in all kinds of forms and then they're interviewed. Even if they're really good, they can't be sure of being chosen - there are so many to choose among. It's great, I mean, anyone can fuck and get pregnant - but these people are the chosen ones, they're the best. I want them for my children.'

One night she knocked on the door. 'It's time, I'm off'. And she left. Two days later the telephone rang and a man told me that Maria wanted to talk to me. She was so under the influence of heroin that I could barely hear her. 'I had a girl', she said. The man came back on the line. 'She isn't feeling very well', he said. I asked him to bring her to the shelter. They came. I took care of her, washed her, gave her something to drink, put her to bed. She slept for about 24 hours and then left the shelter. I never saw her again.

Maria taught me, a young, inexperienced and childless social worker, a great deal. First and foremost, I learned about the ways in which maternal love can be manifested and what it takes to live accordingly. Just as important, she also gave me insight into the complexities of identifying the meaning of the term 'sensitive topic'. Before I met her, I generally considered a person's sexual life as private and a potentially sensitive issue for a researcher. I think this notion was very much in line with my middle-class, Lutheran upbringing. I thought of sensitive topics as established facts. I considered questions like 'Which part of the country do you come from?' or 'Do you like the new TV series?' classic examples of non-sensitive topics, and therefore well 
suited to serve as an invitation to small talk and at the same time indicate an interest in the other person. Maria taught me that it could be quite the reverse; what is sensitive to one person might not be the same for another. All of a sudden, it seemed to me that any topic might be a sensitive one.

\section{Content of the chapter}

So, what is a sensitive topic? That this question might not have a simple answer is, in fact, the main point of this chapter. I will make the claim that what is a sensitive topic and what is not is due mainly to relational circumstances, that is, the relationships between the teller and the listener. In the opening story about my encounter with Maria, I have already introduced some of the main factors that such a relationship includes, such as cultural and contextual circumstances and the personal views held by the people involved. During the course of this chapter I will focus on factors such as power and space and I hope to be able to provide some insight into why these concepts play such a profound role in shaping the relational circumstances for research on sensitive topics.

In the second part of the chapter I will raise the question: 'What kind of methodological steps do we as narrative researchers have to take when dealing with sensitive issues?' Since I have relied mainly on interviews throughout my work, I will focus on the research interview and include some examples from my research on domestic violence. As a point of departure I will present my idea of the ideal interviewer. In my opinion, he or she is more a listener than a questioner. Correspondingly, my ideal interviewee is a person who is a good narrator. My ideal interviewer and also my ideal narrative researcher - is a person equipped with the essential skills to assist the interviewee in his or her efforts to narrate.

The first point I want to make is that as a researcher dealing with sensitive topics you are always at risk of your interviewees positioning you as superior to them. This is due mainly to the fact that they might be telling you about issues they are ashamed of, issues that might be rated culturally low, or events that have left them vulnerable. A researcher explicitly positioned as superior is at risk of meeting resistance from an interviewee that is manifested in various ways of avoidance. This will seriously limit your research. 
My second point is that as a researcher of sensitive topics, and this is very true if you are a researcher of domestic violence, you are always at risk of being so preoccupied with the sensitive and painful that you more or less conceal your interviewees in their suffering. That is, the interview focuses entirely on the dark side of your interviewee's life, which may cause suffering and seriously limit your research.

I will end the second part of the chapter by expanding my analysis to the potential harm the circulation of narratives on sensitive topics may cause the involved, since they might be reinterpreted beyond the narrator's control.

In the third and final part of the chapter, I will emphasize the importance of making physical and discursive space for sensitive topics to evolve in narrative research.

\section{What is a sensitive topic?}

Before I continue, I think it is important to emphasize the difference between an event that involves sensitive, even traumatic, experiences and a sensitive topic. An event is something you experience and a topic is something that appears in a discussion and is dealt with discursively. An event that involves a traumatic experience has the potential to form a sensitive topic, without necessarily doing so. Talk about a traumatic experience, for example, has the potential to pose a threat and even has the potential to re-traumatize the traumatized, but such talk can just as well have the potential to heal. This chapter deals with sensitive topics that may appear and need to be dealt within the context of research.

Textbooks on research methods rarely deal explicitly with the issue of researching sensitive topics. There are no entries for 'sensitive' or 'sensitive topics' in commonly used textbooks such as Handbook of Interview Research (Gubrium and Holstein, 2002) or The Sage Handbook of Qualitative Research (Denzin and Lincoln, 2005). When the question of sensitivity is considered, it is often approached from the perspective of ethics (e.g., Johnson, 2002). The Oxford Dictionary of English (2005) entry for 'sensitive' reads: 'easily damaged, injured, or distressed by slight changes, having or displaying a quick and delicate appreciation of others' feelings, easily 
offended or upset'; thus, 'sensitive' has to do with personal characteristics rather than certain topics.

One of the few books on research methodology that explicitly deals with sensi-tivity is Researching Sensitive Topics, by Renzetti and Lee (1993). The authors define a sensitive topic as 'one that potentially poses for those involved a substantial threat, the emergence of which renders problematic for the researcher and/or the researched the collection, holding, and/or dissemination of research data' (1993: 5). They bring up the issue of whether all topics could carry sensitivity, and come to the conclusion that 'it is probably possible for any topic, depending on context, to be a sensitive one' (1993: 6). Renzetti and Lee continue:

Experience suggests, however, that there are a number of areas in which research is more likely to be more threatening than in others. These include (a) where research intrudes into the private sphere or delves into some deeply personal experience, (b) where the study is concerned with deviance and social control, (c) where it impinges on the vested interests of powerful persons or the exercise of coercion or domination, and (d) where it deals with things sacred to those being studied that they do not wish profaned. (1993: 6)

Renzetti and Lee indicate that sensitive topics basically have to do with personal circumstances. My alternative understanding is that sensitive topics basically have to do with relational circumstances.

\section{Sensitive topics as relationally defined}

Throughout my professional life I have been involved in conversations about sensitive topics. As a social worker I have listened to all kinds of socially embarrassing problems and dilemmas. As a researcher on domestic violence I have dealt with criminal and morally reprehensible deeds, potentially harmful to discuss for victims as well as for perpetrators. Spending my professional life in these two discur-sive domains has given me numerous occasions to reflect on the decisive influence of the outcome of the conversation, the multilayered power relations within and outside the conversation, as well as to consider what kind of discursive and psychical space they were embedded in. Since I have relied on interviews through-out my research work, I have given the relationship between interviewer and interviewee some thought over the years. 
If I had to identify a single factor that has been significant to success in gain-ing access to narratives on sensitive topics, I would mention my growing insight that the process of interviewing can be a jointly conducted enterprise between interviewer and interviewee (see further Bruner, 1990; Mishler, 1986; Riessman, 2002). Accordingly, during the course of several studies based on interviews, I have allowed my interviewees and myself together to actively shape the form of the interviews in a joint process. In such a process, the concepts of 'question' and 'answer' are to be thought of as a part of a circular process, with my informants and I trying to make continuing sense of what we were talking about. This way of conducting interviews differs from standard interviewing, according to which a question with a predetermined meaning serves as a stimulus, intended to elicit a certain response (Mishler, 1986).

If I had conducted my interviews along the lines of standard interviewing, I would most likely have faced considerable difficulties in researching domestic violence, for various reasons. Domestic violence meets several of the criteria identified by Renzetti and Lee (1993) as characterizing topics 'that potentially [pose] for those involved a substantial threat', that is, a sensitive topic. Research on domestic violence (a) is research that intrudes into the private sphere and delves into deeply personal experience and (b) could be concerned with deviance and social control. Another reason why the stimulus-response metaphor would not have served well as a model for conducting my interviews was that they were essentially 'untold stories', stories that had not been told before. Stories of this type are not well suited to a format of pre-prepared questions followed by brief answers. They may fall short entirely and never be articulated. Or, as one man responded to my request for his participation in a study I was conducting on abusive men and battered women:

Yeah, I can be part of your study, I guess. I mean, I have been through a lot, I really have. If you think someone else can be helped by what I have been through, that's good. But I am not sure you will get anything good out of talking with me. The fact is that I don't know anything about what happened (Hydén, 1994: 53).

Despite all the differences that exist between the interviews with the abusive men and abused women I spoke with, they were similar in the sense that in most cases what I asked them concerned previously 'untold stories' and something they 'did not know anything about'. The significance of the difference between 'having been through a lot' and 'knowing about' what 
happened is that of reflection and giving meaning to an experience. This difference is decisive when it comes to research interviewing: without having experienced the cognitive process of 'having been through' an experience and rendering it some meaning so you 'know about it', it is difficult to discuss the experience.

\section{Sensitive topics as culturally defined}

My introductory story reflects my understanding of the relationship between teller and listener as the defining factor for what is a sensitive topic and what is not. It also reflects the culturally situatedness of this relationship; the sensitive topics were brought into our conversation as Maria violated a series of culturally defined norms. First, sensitive topics in the capacity of intimate topics should not be discussed in public, or with unknown persons. They can be discussed in intimate relationships such as between a couple, within the family, or with a close friend - this type of talk even defines such relationships. Second, sensi-tive topics can be discussed in special relationships using special discourses that strip the topics of their intimacy, like doctor-patient discourses (see further Mishler, 1984).

Sex can be linked to intimacy, when a person has learned to feel sexy only when they feel close to someone. The converse is a learned separation between sex and intimacy such that knowing and feeling close to someone makes them sexually uninteresting (Jamieson, 1988). 'A question to ask is whether sex is becoming more or less tied to intimacy, as are questions around gender differences. Are we witnessing the decline of macho-male masculinity with its predatory sexuality that ritually denies intimacy?' Lynn Jamieson (1988: 107) asks, as she traces personal relationships in modern societies.

Prostitution is a form of sexual behaviour in which sex is separated from intimacy. According to prevailing cultural norms, this separation is taken too far. The dominant discourses deprive a narrator like Maria of the possibility of positioning herself as a responsible person who consciously condemns her actions. Predominant discourses position her as a prostitute, a vocation imposed on her from outside: she is the victim of patriarchy; she might have been victimized by men who sexually abused her in her childhood; she might be the victim of her addiction to drugs which works in two directions - she might be in need of money to finance her drug use and she 
might be able to sell sex because she is under the influence of drugs. These discourses make her one of us: she connects sex and intimacy, as the norms prescribe, but she cannot live accordingly for reasons beyond her control. Maria did not speak within these discourses at all, instead violating a series of culturally established norms in her talk.

\section{Sensitive topics defined by power relations}

The interpretations of cultural norms play profound roles in shaping not only the relationship between teller and listener, but also the power relation between the two. Social work practice exemplifies this distinctly.

As a social worker, I was involved in conversations concerning a range of sensitive topics. Sometimes I met people because of their requests for state support, or because they had been reported on suspicion of having neglected their children. Sometimes I met young people because they had been reported for various kinds of misconduct, such as drug use, or different types of destructive behaviour. In these conversations I was explicitly involved in a power relation that put me in the dominant position and the helpseeking or reported person in a subordinate role.

In the context of social work practice, everything can be sensitive due to this pattern of the distribution of power. At a meeting with the powerful and repressive state, a client may have reason to fear that everything he says or does can be held against him. What we social workers try to do is convince our clients that our main mission is not to be repressive, but helpful. As representatives of a welfare state with considerable resources, we definitely have the possibility to play a significant role in people's well-being. In this context, our authority can first and foremost be at our clients' disposal when it comes to matters such as providing counselling or furnishing them with financial support for realizing various needs. In most cases, it turns out well. In others it does not and we are turned away, left alone with our efforts to do good. From experiences like these I learned that power truly is relational. There I was with all the power the state had assigned me, and the presumed powerless client could just say 'no' to what I had to offer and I could do nothing. 'There are no relations of power without resistance', Foucault (1980) states - 'it exists all the more by being in the same place as power; hence like power, resist-ance is multiple and can be integrated in global strategies' (1980: 142). Foucault's insight 
can hardly be more clearly manifested than when the communication between social worker and client breaks down. However, as a young social worker, I struggled with the unequal distribution of power that permeates every part of social work practice. Little did I imagine at that time the even more complex kinds of power relations that characterize research on domestic violence.

\section{Dealing with sensitive topics in narrative research}

The research interview as a power relation

As a social worker, I became very well aware of the imbalance in power between my clients and myself. When I first reflected on the matter as a researcher on family violence, the case seemed to be quite the reverse: I was the dependent one. My informants were in the dominant position and I was the subordinate. I was the one who asked them for something that was valuable to me, i.e. their experiences. Later I came to understand that it was more complex than this. Since I, as a researcher, held a culturally highly valued position and they, as battered women or abusive men, were asked to tell me about self-experiences that were culturally of low value, our power relation was not as different from the one of social worker-client as I first thought. One woman vividly expressed her apprehension in seeing herself as culturally a woman of low value - as well as the reason for her evaluation:

To think of yourself as a battered woman ... that is almost impossible. I feel so ashamed ... to me, a battered woman is an unloved woman. I think this is why a woman doesn't want to go to the grocery store with a black eye. She doesn't want people to think: 'See', there is a woman whose husband beats her'. It's simply a way to protect yourself. (Hydén, 1995: 131)

It was not the violence as such that placed her in a culturally low position but the message it carried: you are unloved.

Over and over, the battered women I have interviewed have taught me the sig-nificance of being involved in activities of culturally low value - even if you were forced into them, even if you were a victim of them:

I don't like to talk about the fact that I have been beaten. You see, I haven't had a good childhood either. If you haven't had that, no one ever gives you a chance. I think one should look forward, but no one else seems to think so. If they find out that there is a lot of misery at hand, they think they really know something about you. Just get down 
in all the old damned trash and stay there, that's what they want you to. I hate it when the decent and clever people feel sorry for you. They look as if no one has ever been awful to them. I can see immediately what they think: There's someone who is inferior to me. (Hydén, 1995: 132)

These two women's words made a deep impression on me. I had a reason to recall them some years later when I was studying battered women's break-ups. My informants were a group of women I first met at the Women's Shelter in Stockholm, Sweden, and then on six separate occasions over a two-year period. I had reflected upon the fact that I, as an academic researcher, was probably quite highly ranked, and considered what this might mean in my encounters with these women. I had come to no significant conclusion, when one of the women approached me one day with some other women giggling behind her: 'May we ask you something?' 'Sure'. 'They say that you're divorced - is that true?' 'Yes it is'. This confirmation seemed to make everyone very happy! The giggling increased and I heard them say: 'So it's true that Margareta Hydén is divorced! Amazing! She seems so competent and clever, but she's also a failure when it comes to marriage! She's just like us!'

Over the years, I let the two women's words and similar words from other women encourage me to take my research in a direction that not many had taken before me. It occurred to me that I was in the danger zone of being just another person, luring the women to 'get down in all the old damned trash and stay there', or, as bel hooks (1999) so vividly puts it, I was at risk 'of concealing the woman into her suffering. In series av articles $(199 ; 2005 ; 2008)$ I have traced the women's suffering as well as their strategies of resistance, including what I have called 'the process of leaving'. What is important in these studies, which include sensitive topics, is the focus on what has not been said and why, as well as on what has been said. The two women taught me that if interviews that include sensitive topics deal principally with 'damned old trash', they are potentially harmful, and a basic feature of the sensitive topic of being the victim of domestic violence, for example strategies of resistance, is left out.

\section{Circulation of narratives on sensitive topics as potentially harmful}

Having reflected on the power relation that constitutes the interview setting, we must now consider the wider context of the interview and the power relations it carries. The aim of all research is to circulate its results to audiences often far from the interviewees, but it is important 
to remember that audiences close to them may also pay attention. In order to protect the interviewees, basic methodological and ethical codes require the alteration of names and other circumstances that may make identification possible. The circumstances of research results being cir-culated to an audience far 'out there' have been quite uncomplicated for most of my interviewees. In fact, it has been one of the main reasons for their participation. Like the man I interviewed in a study on abusive men and battered women put it: 'If you think someone else can be helped by what I have been through, that's good' (Hydén, 1994: 53). More problematic was the imaginable audience close to him, like the police. Most of the abusive men I interviewed were under investigation by the local police and wanted to know if they could under any circumstance demand access to my files.

Other researchers have had similar experiences. In her study of marital rape, Diana Russell (1990) found that many women were hesitant to disclose informa-tion to her for fear that their husbands might read her work. John Brewer (1993) received a positive response from the authorities, but a quite hostile response from his intended informants, when he implemented his ethnographic study of routine police work by the Royal Ulster Constabulary in East Belfast, Northern Ireland. The policemen and women were afraid that Brewer's writings could harm them, if used by the IRA or the authorities. Brewer concluded that 'the issue of sensitivity needs to emerge from the shadows and be recognized as an important problem in research, so that social researchers can give more attention to its negative effects' (Brewer, 1993: 143). Narratives are always open to reinterpretation. By passing them on to new audiences, we pave the way for possible new meanings - and as they are passed on, they make entrance into new power relations.

A tragic outcome of such a transference was related to me in a study I conducted, entitled 'To talk about sexual abuse and other difficult experiences', concerning the treatment of young girls in compulsory youth care. At the institution, there was a general agreement among the staff that if memories of sexual abuse were repressed and never came out into the open, the young women would become self-destructive and, for instance, injure themselves. Untold, the story was seen as dangerous in that although it was not verbalized, it was nevertheless presented in a fragmented form inside the young woman, casting her in her own eyes as someone repulsive and worthless, responsible for her own victimization. Consequently, the staff tried to trace signs of suspicious 
sexual abuse, thereafter allowing and encouraging talk about the sexual abuse. The main purpose of this was not to circulate the story - quite the contrary - it was told under professional secrecy. But the message was quite clear. Stories of sexual abuse must be told, or they will harm you. The following story demonstrates how problematic this message can be, due to the lack of control over the wider circulation of the story and the reinterpreta-tions it may undergo. The teller is a female staff member at the institution:

And she [a 15-year-old girl at the institution] said things like in the end she wanted to have a pregnancy test after she'd been at home. We knew she'd just been home with mum and dad and not gone out or anything. So it was ... well it was like that.

When she got home, her dad would send her mum out to walk the dog. And he'd take her down to the root cellar and abuse her sexually. So it was under pretty grotesque conditions you know. It had been going on for a number of years and all that kind of stuff, yeah, so I think ...

When she told and there was a trial and all that but then she got she got completely you know ... disowned by her family, you know, her brothers and sisters refused to have any contact and she ended up in the mental hospital. I think now she's committed suicide.

It's really difficult.

It's really difficult.

(Överlien and Hydén, 2003: 231)

What was supposed to be a healing narrative turned out to be a harmful one. It moved away from the closed space of the institution and reached the powerful space of the courtroom, was retold and reinterpreted and in its new form reached the private family sphere it once came from - in a different form. From the family's perspective, the narrative was never meant to leave the private sphere and be transformed in the courtroom.

\section{Making space for sensitive topics}

The very sad story about the young woman who committed suicide after disclos-ing her father's sexual abuse and being disowned by her family can serve as one of many illustrations in this chapter of the complex power relations in research on sensitive topics. It may also serve as an illustration of the second factor, that is, space, which in close relation to power, plays such a 
profound role in shaping research that includes sensitive topics. The story told in the courtroom is never the same as the one told in the family.

My second more comprehensive study on domestic violence concerned women who had left their violent husbands (e.g. Hydén, 1999, 2005, 2008). From that study, among other things, I learned the profound importance of space in narrative studies on sensitive topics.

\section{Offering physical space}

Generally speaking, breaking up is about difference and movement. When you break up, you stage discontinuity in time and location/physical space. You leave, you depart from something or someone. When a battered woman leaves her husband, she leaves their joint home. At the same time as she changes her physical space, she changes her discursive space. This self-inflicted disruption, this difference she has administered to herself, gives her an opportunity to (re)form her life history.

The Battered Women's Shelter in Stockholm, Sweden, is a special place in that it offers housing and support to women in exile after they leave abusive relationships. In doing so, it offers physical space for all kinds of practices aimed at liberating women from an oppressive man and a patriarchal society. In this, it also offers a discursive space for all kinds of conversations about what happened in the past and wishes for the future. For many women, their time at the shelter represents a turning point, well suited for reflection, creating an ideal space for research based on interviews.

The Youth Detention Home for Girls did not offer a similar ideal space. The girls were incarcerated in a disciplinary space and much of their energy was aimed at maintaining distance and acquiring some degree of freedom and control. In this setting I focused mainly on the staff, trying to understand how they attempted to create a space aimed at healing within the institution. However, something unexpected happened when my doctoral student, Carolina Överlien, and I had been present for some time; the girls became increasingly curious and irritated because we only paid attention to the staff and not to them. Basically, to meet their wishes, we decided to include them in the research. This idea was not met with much enthusiasm by the staff. 'It will 
fail', they said. 'The girls don't want to sit down and talk, and even if they want to, they are not able to - too vulner-able, in too bad shape physically. In addition, they may be very violent, there is a security issue involved here.' Since the girls had more or less asked to be involved I decided to go ahead, at the same time taking the staff's worries into account. What I was aiming for was to transfer the disciplinary space into a physically and discursively more open space, where stories could be elicited.

\section{Offering discursive space}

I planned a series of focus groups under the heading 'To be a young woman in Sweden'. I asked Carolina to be the leader and to choose stimulus material from journals about all kinds of pleasure and problems that might constitute a young Swedish woman's life. I instructed her to be very liberal when it came to attendance - if a girl wanted to leave the group and return, this would be all right.

I chose a group format because personal interviews, especially when it comes to sensitive topics, can be quite intrusive. I chose the overall topic for the focus groups relevant to the study, but it was still open enough for the girls to shape the conversations as they wished. I chose the liberal come-and-go rules to offer them an additional opportunity to shape the situation along their own lines. I did this for methodological reasons - without the creation of an open discursive space I was convinced that the girls would not have been able to talk; I did it for ethical reasons as well I did not want to harm the girls, I wanted to give them a good experience.

Following these procedures, one of the things the girls liked to talk about concerned themselves as future mothers. There was an obvious rift here between the discourses of the girls and the staff; the latter drew on discourses about sexuality in their interviews, discourses that were problemoriented and failed to recognize the young women as future mothers. Although the girls were placed in custody because of drug problems and crime, their case notes focused on identified 'problems' - in particular their experiences of sexual abuse. As the prevailing problemoriented sexual abuse discourse did not regard women's sexuality as active and consensual, childbearing and motherhood were not discussed. Thus, the risk of pregnancy was discussed by the staff and treated as a problem with a solution; the staff administered birth control pills and 
condoms. In the focus group sessions, the question of childbearing and motherhood took up a considerable amount of time, since the girls wanted to discuss things like their emotional longing for children, what is needed to take care of them, and how to handle demands from children with their own wishes 'to explore life and have fun' - topics most young women are concerned with (Överlien and Hydén, 2004).

\section{Offering discursive space by challenging the narrative performance}

In my first study on domestic violence (see, for example, Hydén, 1994), I sometimes tried to open up a discursive space by challenging versions of the abuse story that I found too narrow, or too lacking in coherence and logic. In most cases I did this by quietly calling into question what had been said and suggesting further exploration. In some cases I did not act that quietly, but rather showed my non-acceptance in a more direct way. I must admit that when I first acted in this straightforward way, I had not devoted myself to much reflection on whether or not this was in accordance with my idea of the ideal interviewer I was very eager to become. My straightforwardness simply came to me after I had experienced an increased state of irritation at listening to the abusive men's stories that I came to think of in terms of 'rhetoric of exculpation or narratives of disclaimed actions', or 'the story of how someone else beat my wife'. The storyline was something like 'My wife has been beaten (severely in most cases) and I am very sorry, but I cannot be responsible because...' One man often returned to his favorite story:

IP: You see, in our heads there is a place with two poles. There has to be a certain distance between them. When you get angry, you get close to one of the poles. In my head, the poles are too close together, so that when I get angry, they crash into each other. I can see on your face that you don't believe me, but it is in fact true. A doctor himself told me this. I think it was caused by a motorcycle accident I was in.

M: How can you tell when this happens?

IP: I simply have a total blackout. I get mad and then BANG, it crashes and I am not aware of anything for a long time. When I come to again, I have often done something violent. Hit Pia (his wife) or trashed the apartment.

Then I posed the question that made his story follow another direction:

M: Then it must be unbelievable luck that Pia is still alive.

IP: What do you mean? 
M: I mean that when you get mad at her and it short-circuits in your head, your body takes on a life of its own and becomes violent. It's lucky that you haven't stuck the bread knife in her, or scissors, or hit her even worse than you have.

IP: Are you crazy or something??!! Do you really think I could do such a thing? I would never hurt her that bad. (Hydén, 1995: 58)

After he was confronted in this way, his account became more detailed. By chal-lenging his narrative and drawing it to its extremes, I created the possibility for other narratives to be told about the violent events. These narratives were much more complex and also included his responsibility.

\section{Offering discursive space by empowering the narrator}

I cannot claim that my repertoire for opening discursive space is generally characterized by a confrontational style - quite the contrary. My years of studying sensitive topics have rather given me a constantly growing repertoire of ways to support and empower my interviewees - for methodological, ethical and humane reasons - and not challenge them. Presently, I am working on a study of children who have witnessed violence in their home. This study is one of the most difficult studies I have ever worked with, and has given me reason to further develop my repertoire of supportive attitudes. What these children are going through and the straightforward way they talk about it is very difficult to listen to. I chose 'empowerment' as my closing remark not only because it is an important topic for the informants, but also because it is important for me and my fellow researchers who study sensitive topics. Studying sensitive topics is a relational state of affairs in more ways than one. It emotionally affects the informant as well as the researcher. They both need to be empowered from time to time, or they risk 'getting down in all the old damned trash and staying there'. My last example, taken from the study of children who have witnessed violence in their home, aims at illustrating how such an empowerment can be manifested.

The excerpt is taken from an interview with Christine. She is 15 years old and has experienced her stepfather's severe violence towards her mother and some-times towards herself. She has had a hard time at school and has been bullied. These living conditions brought her to the brink of suicide, but she was saved at the last minute. She is very emotionally affected during the 
interview and I stop her at several points, asking her if it is $\mathrm{OK}$, if she really wishes to continue, and she says she does. I become more and more worried, however, that she is 'getting down there' a bit too deep. So I decide to intervene and open the space for another story to be elicited, a story that might empower her a bit more:

M: Have you ever thought that there are other children who have been exposed to almost the same as you, do you know that?

C: Yes, it's a lot actually

$\mathrm{M}: \mathrm{Mmm}$

C: When I think of it ... it's almost fun, that so many have the same problem, it's less lonesome

M: Just think of what a huge political party you and the others could start

$\mathrm{C}: \mathrm{Mmm}$

M: Then one becomes a bit happier

C: Then you think that you're not alone. When you're deep down there you think you're totally alone, but then ... I wonder how many it actually is?

M: You can think of it when you take the bus from school

C: Today it was nice weather, I was thinking about that and was happy. But when it snows or rains, I hate it

M: Next time it rains and you're on the bus, think of it then

C: (smiling) Yeah, and if you count every seat in the whole bus, I think it might be $15 \%$

M: (smiling) Yeah, and then you can count the next bus, and the next and the next ...

My intervention is quite powerful. I interrupt Christine's talk by introducing a new topic. The interruption is deliberate, as is the choice of topic. From several years of researching domestic violence I have learned that exposure to violence is embedded in feelings of vulnerability and powerlessness, due to the fact that neither the victim nor anyone else has been able to offer protection. The feelings of vulnerability and powerlessness are therefore closely linked to feelings of loneliness, which is further stressed because it is not culturally acceptable to be exposed to domestic violence.

What I acted on in the interview with Christine was my apprehension at her increasing vulnerability and suffering. I also understood her as someone who was not very good at taking care of herself and stopping before our conversation became too painful - and this for many reasons: she was young and inexperienced; she had not had much assistance during her childhood in supporting herself; she was very ambitious and wanted to give a good interview; and she had 
not had many encounters with people who truly wanted to listen to her, so she wanted to use this chance to talk. I acted because I wanted to save Christine from another painful experience. I decided to 'rewind the tape backward' and try to substitute loneliness with belongingness and thus provide her with the empowering strength that a group of people with similar experience have to offer each other. Christine's story illustrates how empowering a disruption of feelings of loneliness can be. The group of people she felt kinship with did not even have to be identified; the very notion of their existence was enough to give her - and me - strength and energy. The latter is not the least important to emphasize; for me, the content of what Christine had to tell me was difficult to listen to. I felt I somehow needed to compensate her for the obvious emotional strain I had caused her, and finding a way for her to tell new stories that brought new energy to her, and to me as well.

\section{Conclusion}

During the course of this chapter, I hope I have made my main point quite clear. There is no simple answer to the question 'What is a sensitive topic?' Consequently, my concluding remarks will not offer a definite summary and suggest that the work is finished and complete. Quite the contrary; I would like this conclusion to serve as an opening for others to enter into a dialogue on narrative research and sensitive topics.

I have emphasized that, as in all relationships, the relation between teller and listener in narrative research is a power relation. This feature appears particularly distinctly when sensitive topics are involved. Throughout my research, I have dealt with the sometimes extreme incongruence between a victimized and vulnerable woman and myself, a female, well-off, academic researcher. I have not tried to hide the obvious, but have rather stressed the similarities as well as the differences between us. In the divorce example, the similarity between myself and the women at the Battered Women's Shelter was emphasized - although I had not been exposed to violence, we were 'all failures when it came to marriage'. In the example of the young Christine, the differences between us were emphasized. I used my experience and authority to introduce a new topic. 
Throughout this chapter I have argued that what is a sensitive topic and what is not is mainly dependent on relational circumstances, that is, it has to do with the relationship between the teller and the listener as well as the personal, cultural and contextual circumstances of that relationship. My opening story aimed to illustrate the different values of what is sensitive and what is not that two young women of almost the same age living in the same city can hold, basically because of different personal experiences and different interpretations of cultural norms. The story also illustrated the significance of contextual circumstances for narrative on sensitive topics to evolve. The shimmering heat of the urban Swedish high summer and the isolation at the place emptied for the holiday season hosted the encounter between the two young women who embraced a great number of 'sensitive topics' in their conversations.

Different physical spaces offer different discursive spaces. What could not be said at a battered woman's home could be said at the Battered Women's Shelter, and vice versa. What could not be said in the family could be said in the court-room, and vice versa. I call upon the narrative researcher's interest for further examination of the relational aspects of their work, especially when it includes sensitive issues.

\section{References}

Brewer, J. (1993) Sensitivity as a problem in field research: A study of routine policing in Northern Ireland. In M. Renzetti and R. Lee (eds), Researching Sensitive Topics. Newbury Park, CA: Sage.

Bruner, J. (1990) Acts of Meaning. Cambridge, MA: Harvard University Press.

Denzin, N. and Lincoln, Y. (eds) (2005) The Sage Handbook of Qualitative Research. Thousand Oaks, CA: Sage.

Foucault, M. (1980) Power and strategies. In G. Collin (ed.), Power/Knowledge: Selected Interviews and Other Writings 1972-1977 by Michel Foucault. London: Harvester Wheatsheaf.

Gubrium, J. and Holstein, J. (eds) (2002) Handbook of Interview Research: Context and Method. Thousand Oaks, CA: Sage.

hooks, b. (1999) Remembered Rapture: The Writer at Work. New York: Henry Holt.

Hydén, M. (1994) Woman Battering as Marital Act: The Construction of a Violent Marriage. Oslo: Scandinavian University Press.

Hydén, M. (1995) Kvinnomisshandel inom äktenskapet: Mellan det omöjliga och det möjliga. Stockholm: Liber.

Hydén, M. (1999) The world of the fearful: Battered women's narratives of leaving abusive husbands. Feminism \& Psychology 9, 449-69. 
Hydén, M. (2005) 'I must have been an idiot to let it go on': Agency and positioning in battered women's narratives of leaving. Feminism \& Psychology 15, 169-88.

Hydén, M. 2008) Break-up narratives. In LC Hydén and J Brockmeier (eds.). Health, Illness and Culture: Broken Narratives. Pp 154-168.

Jamieson, L. (1988) Intimacy: Personal Relationships in Modern Societies. Cambridge: Polity Press.

Johnson, J. (2002) In-depth interviewing. In J. Gubrium and J. Holstein (eds), Handbook of Interview Research: Context and Method. Thousand Oaks, CA: Sage.

Mishler, E. (1984) The Discourse of Medicine: Dialectics of Medical Interviews. Norwood, NJ: Ablex.

Mishler, E. (1986) Research Interviewing: Context and Narrative. Cambridge, MA: Harvard University Press.

Överlien, C. and Hydén, M. (2003) Work identity at stake: The power of sexual abuse. Stories in the world of compulsory youth care. Narrative Inquiry 13, 217-42.

Överlien, C. and Hydén, M. (2004) 'You want to have done your living if you know what I mean': Young incarcerated Swedish women speak about motherhood. Feminism and Psychology 14, 226-30.

Renzetti, M. and Lee, R. (eds) (1993) Researching Sensitive Topics. Newbury Park, CA: Sage.

Riessman, C. (2002) Analysis of personal narratives. In J. Gubrium and J. Holstein (eds), Handbook of Interview Research: Context and Method. Thousand Oaks, CA: Sage.

Riessman, C. K. (2005) Narrative in social work. Qualitative Social Work 4, 391-412.

Russell, D. (1990) Rape in Marriage. New York: Macmillan. 